\title{
HUBUNGAN KUALITAS PELAYANAN ANTENATAL DENGAN KELENGKAPAN IBU HAMIL DALAM MELAKUKAN ANTENATAL CARE
}

\author{
Armen Patria*, Gustop Amatiria** \\ *Prodi Keperawatan STIKES Mitra Lampung \\ ** Jurusan Keperawatan Poltekkes Tanjungkarang
}

\begin{abstract}
Angka Kematian Ibu (AKI) di Indonesia masih tinggi yaitu 228 per 100.000 kelahiran hidup. Risiko kematian ibu selama kehamilan dan persalinan dapat dikurangi bila ibu hamil memeriksakan kehamilannya sedini mungkin dan tepat waktu. Penelitian ini bertujuan untuk mengetahui hubungan kualitas pelayanan antenatal dengan kelengkapan ibu hamil dalam melakukan antenatal di Kabupaten Lampung Timur. Penelitian ini adalah penelitian kuantitatif dengan menggunakan desain studi Cross Sectional pada 160 orang ibu yang mempunyai bayi $\leq 6$ bulan dan pernah memeriksakan kehamilannya selama hamil ke 4 puskesmas yang terpilih sebagai sampel. Variabel dependent adalah kelengkapan ibu dalam melakukan antenatal, variabel independent adalah kualitas pelayanan antenatal, Hasil penelitian menunjukkan adanya hubungan antara kualitas pelayanan antenatal dengan kelengkapan ibu hamil dalam melakukan antenatal. Ibu yang menilai pelayanan antenatal yang diterimanya berkualitas cenderung hampir 4 kali untuk melakukan pemeriksaan antenatal secara lengkap dibandingkan dengan ibu yang menilai kualitas antenatal yang diterimanya kurang. Sedangkan variabel kovariat yang bermakna dalam kelengkapan ibu hamil melakukan antenatal adalah variabel pendidikan dan sikap dari ibu. Berdasarkan hasil tersebut maka kualitas pelayanan antenatal perlu ditingkatkan dengan cara melaksanakan pembinaan dan monitoring secara berkala kepada petugas kesehatan, memberikan pelatihan teknis tentang pelayanan antenatal kepada petugas and petugas kesehatan memberikan pelayanan antenatal sesuai standar.
\end{abstract}

Kata kunci: Angka Kematian Ibu, kehamilan, persalinan, antenatal

\section{LATAR BELAKANG}

Angka Kematian Ibu (AKI), Angka Kematian Neonatus (AKN), Angka Kematian Bayi (AKB), dan Angka Kematian Balita (AKABA) merupakan beberapa indikator status kesehatan masyarakat. Di dunia saat ini setiap tahun sebanyak 529000 ibu meninggal akibat masalah yang berkaitan dengan kehamilan dan persalinan. Kematian ibu tertinggi terjadi di wilayah Afrika diikuti oleh Asia Selatan dan Timur sedangkan terendah di wilayah Eropa. (WHO, 2005) Di Negara asia tenggara tahun 2003 seperti Negara Vietnam AKI sebesar 95 per 100.000 kelahiran hidup, Malaysia AKI sebesar 30 per 100.000 kelahiran hidup, dan Singapura AKI 9 per 100.000 kelahiran hidup (Siswono, 2003, Depkes RI, 2005). AKI di Indonesia masih tertinggi dibandingkan dengan negara ASEAN lainnya. Menurut data Survei Demografi Kesehatan Indonesia (SDKI) 2007, di Indonesia AKI 228 per 100.000 kelahiran hidup (PWS-KIA, 2009). Penyebab utama kematian ibu adalah perdarahan (30\%), eklamsia (25\%) dan infeksi (12\%) (SKRT 2001).

Pada Tahun 2000 Pemerintah Indonesia telah mencanangkan Making Pregnancy Safer (MPS) yang merupakan strategi sektor kesehatan secara terfokus. Fokus strategi MPS adalah untuk meningkatkan kemampuan sistem kesehatan dalam menjamin penyediaan dan pemantapan pelayanan kesehatan yang ditujukan untuk menanggulangi penyebab utama kematian dan kesakitan ibu dan bayi baru lahir dengan 3 (tiga) pesan kunci yaitu: Setiap persalinan ditolong tenaga kesehatan, setiap komplikasi obstetrik dan neonatal ditangani secara adekuat dan setiap wanita usia reproduksi mempunyai 
akses terhadap pencegahan kehamilan yang tidak diinginkan dan penanggulangan komplikasi abortus tidak aman (Depkes RI, 2001).

Upaya kesehatan yang mempunyai daya ungkit terbesar dalam menurunkan angka kematian ibu dan angka kematian bayi baru lahir adalah pemeriksaan dan pelayanan kehamilan yang baik yang sering disebut pelayanan antenatal yang bermutu. Pemeriksaan antenatal adalah pemeriksaan kehamilan yang dilakukan untuk memeriksa keadaan ibu dan janin secara berkala, yang diikuti dengan upaya koreksi terhadap penyimpangan yang ditemukan serta mendidik dan memotivasi ibu hamil agar merawat dirinya dan mempersiapkan persalinannya. Pemeriksaan antenatal dilakukan oleh tenaga terampil dalam bidang kebidanan bertujuan untuk menjaga agar ibu hamil dapat melalui masa kehamilan, persalinan dan nifas dengan baik dan selamat serta menghasilkan bayi yang sehat.

Berdasarkan hasil SDKI (2007) diketahui ibu-ibu yang memeriksakan kehamilannya lebih dari 4 kali lebih memilih persalinan di fasilitas kesehatan (54\%) dibandingkan yang memeriksakan kehamilan 1-3 kali hanya $20 \%$ yang memilih bersalin di fasilitas kesehatan. Penelitian di RS Dr.Pirngadi Medan, ditemukan kematian maternal pada 93,9\% kelompok tidak terdaftar (kelompok ibu yang memeriksakan kehamilannya kurang dari 4 kali selama hamil), sedangkan penelitian Tobing tahun 1984-1989 menemukan kematian maternal pada $67,9 \%$ kelompok tidak terdaftar. Penelitian pada ibu hamil di Jawa Tengah tahun 1989-1990 menemukan bahwa ibu hamil dan bersalin yang tidak memeriksakan kehamilannya pada tenaga medis akan mengalami risiko kematian 3-7 kali dibanding ibu yang memeriksakan kehamilannya (Roeshadi, 2004)

Berdasarkan hasil Survei Demografi dan Kesehatan Indonesia tahun 2007 diketahui kualitas Antenatal Care (ANC) berdasarkan jenis pelayanan yang diberikan petugas pada waktu melakukan ANC yaitu: mendapat info tentang bahaya
(38.8\%), timbang berat badan (90.7\%), ukur tekanan darah $(91.9 \%)$, pemeriksaan abdomen (96.00\%), periksa urine $(40.1 \%)$, periksa darah (29.2\%). Berdasarkan data tersebut diketahui jenis pelayanan terbanyak yang dilakukan petugas pada saat melakukan ANC adalah pemeriksaan abdomen dan masih sedikit sekali yang memberikan info tentang tanda bahaya pada kehamilan, persiapan persalinan dan komplikasi. Pada umumnya, wanita yang lebih tua, wanita yang melahirkan lebih banyak, wanita pedesaan dan wanita dengan pendidikan lebih rendah, cenderung kurang mendapatkan pelayanan pemeriksaan kehamilan lengkap (SDKI 2002-2003)

Pelayanan antenatal pada dasarnya merupakan interaksi antara pengguna jasa (ibu hamil) dan penyelenggara pelayanan (puskesmas). Interaksi yang terjadi sangat dipengaruhi berbagai faktor sehingga merupakan hal yang komplek, karena itu penulis ingin mengetahui bagaimana hubungan kualitas pelayanan antenatal yang diberikan petugas dengan kelengkapan ibu hamil dalam memeriksakan kehamilannya.

Cakupan pelayanan ANC (K4) di Kabupaten Lampung Timur belum mencapai target dan belum diketahuinya kualitas pelayanan antenatal dimana masih didapat puskesmas yang mempunyai kesenjangan KI dan K4 melebihi $10 \%$ (Puskesmas Jabung, Puskesmas Labuhan Maringgai dan Puskesmas Sribhawono) namun ada Puskesmas yang mempunyai kesenjangan K1 dan K4 kurang dari 10\% yaitu Puskesmas Sukadana, Puskesmas Wana, Puskesmas Peniangan, Puskesmas Trimulyo dan Puskesmas Margoto, di Kabupaten Lampung Timur sehingga menarik minat peneliti untuk mengetahui hubungan antara kualitas pelayanan antenatal dengan kelengkapan ibu hamil dalam melakukan pemeriksaan kehamilannya di 4 Puskesmas (Puskesmas Labuhan Maringgai dan Puskesmas Sribhawono, Puskesmas Wana dan Puskesmas Peniangan) Kabupaten Lampung Timur, mengingat pentingnya antenatal yang berkesinambungan untuk 
meningkatkan derajat kesehatan ibu dan bayi. Keempat Puskesmas tersebut dipilih berdasarkan peringkat jumlah kasus kematian ibu yang terjadi di kabupaten Lampung Timur dimana kasus kematian ibu Puskesmas Sribhawono 2 kasus, Puskesmas Labuhan Maringgai 1 kasus, Puskesmas Wana 1 Kasus dan Puskesmas Peniangan 0 kasus (Dinkes Lamtim, 2010).

\section{METODE}

Penelitian ini menggunakan pendekatan kuantitatif dengan desain cross sectional, yang mempelajari hubungan antara variabel independent dengan variabel dependent, dimana variabel-variabelnya diambil pada saat yang bersamaan. Saat yang bersamaan disini maksudnya adalah tiap subyek hanya diwawancarai satu kali saja dan variabel independent serta variabel dependent diukur pada saat wawancara tersebut. Wawancara dilaksanakan dengan menggunakan kuesioner yang telah disusun dan telah dilakukan uji Validitas dan realibilitas.

Hasil uji validitas dan reliabilitas terhadap pertanyaan tentang pengetahuan (pertanyaan no. 13-24) diperoleh $r$ minimal 0,466 dan $r$ alpha 0,964 ; pertanyaan tentang sikap (pertanyaan no. 25-34) diperoleh $r$ minimal 0,424 dan $r$ alpha 0,844 ; pertanyaan tentang dukungan keluarga (pertanyaan no.35-38) diperoleh $\mathrm{r}$ minimal 0,392 dan $r$ alpha 0,821 ; pertanyaan tentang kebutuhan diperoleh $\mathrm{r}$ minimal 0,894 dan $\mathrm{r}$ alpha 0,972 dan pertanyaan tentang kualitas (pertanyaan no. 45-86) diperoleh $\mathrm{r}$ minimal 0,481 dan $\mathrm{r}$ alpha 0,990. Sedangkan $r$ tabel dengan taraf signifikan 5\% adalah: 0,361 sehingga dapat ditarik kesimpulan secara statistik bahwa kuesioner dalam penelitian ini valid dan reliabel.

Data yang dikumpulkan pada penelitian ini berupa data primer yang diperoleh dari hasil wawancara dengan seluruh responden yang telah ditetapkan. Pengumpulan data ini dilakukan oleh peneliti dan dibantu oleh petugas dinkes Provinsi Lampung sebanyak 3 (tiga) orang dan 1 (satu) orang dari dinkes Kabupaten Lampung Timur yang sebelumnya sudah dilatih dalam mengisi kuesioner.

Tahapan proses pengolahan data dimulai setelah kuesioner terkumpul kemudian data diolah melalui proses editing data, scoring data, pengkodean data, membuat struktur data dan file data, entry data dan cleaning data. Selanjutnya dilakukan analisis. Analisis yang digunakan adalah analisis univariat dan analisis bivariat..

Analisis bivariat dilakukan untuk mengetahui hubungan antara variabel independent, variabel kovariat dan variabel dependent. Uji yang akan digunakan adalah uji kai kuadrat karena masing-masing variabel sudah dikatagorikan.

\section{HASIL}

\section{Analisis Univariat}

Tabel 1: Distribusi Frekuensi Kelengkapan dalam Melakukan Antenatal Care

\begin{tabular}{lcc}
\hline \multicolumn{1}{c}{ Kunjungan Antenatal } & $\mathrm{f}$ & $\%$ \\
\hline Lengkap & 95 & 59.4 \\
\hline Tidak Lengkap & 65 & 40.6 \\
\hline \multicolumn{1}{c}{ Jumlah } & 160 & 100 \\
\hline
\end{tabular}

Berdasarkan pengelompokan kelengkapan dalam melakukan antenatal didapat bahwa, tidak terlalu jauh perbedaan antara responden yang melakukan kunjungan antenatal secara lengkap dengan responden melakukan kunjungan antenatal tidak lengkap.

Tabel 2: Distribusi Frekuensi Responden Berdasarkan Kualitas Pelayanan Antenatal

\begin{tabular}{|c|c|c|}
\hline Kualitas Antenatal & $f$ & $\%$ \\
\hline Baik & 78 & 48.8 \\
\hline Kurang & 82 & 51.3 \\
\hline Jumlah & 160 & 100 \\
\hline
\end{tabular}


Berdasarkan pengelompokan kualitas pelayanan antenatal, didapatkan bahwa hampir tidak ada perbedaan antara responden yang menyatakan kualitas pelayanan antenatal, baik dengan responden yang menyatakan kualitas pelayanan antenatal kurang baik.

Tabel 3: Distribusi Frekuensi Responden Berdasarkan Variabel Kovariat

\begin{tabular}{lcc}
\hline Variabel Kovariat & f & $\%$ \\
\hline Umur & & \\
\hline Tidak Beresiko & 138 & 86 \\
\hline Beresiko & 22 & 14 \\
\hline Pendidikan & & \\
\hline Tinggi & 82 & 51 \\
\hline Rendah & 78 & 49 \\
\hline Pengetahuan & & \\
\hline Baik & 92 & 58 \\
\hline Kurang & 68 & 42 \\
\hline Paritas & & \\
\hline Sedikit & 137 & 86 \\
\hline Banyak & 23 & 14 \\
\hline Pekerjaan & & \\
\hline Bekerja & 63 & 36 \\
\hline Tidak berkerja & 97 & 61 \\
\hline Sikap & & \\
\hline Positif & 77 & 48 \\
\hline Negatif & 85 & 52 \\
\hline
\end{tabular}

Berdasarkan

pengelompokan

kualitas pelayanan antenatal, didapatkan bahwa hampir tidak ada perbedaan antara responden yang menyatakan kualitas pelayanan antenatal baik dengan responden yang menyatakan kualitas pelayanan antenatal kurang baik.

\section{Analisis Bivariat}

Tabel 4: Hubungan Kualitas Pelayanan Antenatal dengan Kelengkapan Ibu hamil dalam Melakukan Kunjungan Antenatal Care

\begin{tabular}{|c|c|c|c|}
\hline \multirow{3}{*}{$\begin{array}{c}\text { Kualitas Pelayanan } \\
\text { Antenatal }\end{array}$} & \multicolumn{2}{|c|}{$\begin{array}{c}\text { Kelengkapan } \\
\text { Antenatal }\end{array}$} & \multirow{2}{*}{ Total } \\
\hline & Lengkap & $\begin{array}{c}\text { Tidak } \\
\text { Lengkap }\end{array}$ & \\
\hline & $\%$ & $\%$ & $\%$ \\
\hline Baik & 6279,5 & $16 \quad 20,5$ & $78 \quad 100$ \\
\hline Kurang & 3340,2 & $49 \quad 59,8$ & $82 \quad 100$ \\
\hline p value & \multicolumn{3}{|c|}{0,000} \\
\hline OR 95\% CI & \multicolumn{3}{|c|}{$5,754(2,8-11,6)$} \\
\hline
\end{tabular}

Hasil analisis bivariat untuk melihat hubungan kualitas pelayanan antenatal dengan kelengkapan ibu hamil dalam melakukan antenatal di 4 puskesmas Kabupaten Lampung Timur tahun 2009, maka berdasarkan hasil uji statistik diperoleh nilai $\mathrm{P}=0,000$ maka dapat disimpulkan ada hubungan antara kelengkapan ibu hamil dalam melakukan antenatal dengan kualitas pelayanan antenatal. Analisis keeratan hubungan dua variabel didapat $\mathrm{OR}=5,75(95 \%$ CI 2,8 11,6) artinya responden yang menilai kualitas pelayanan antenatal baik mempunyai kecenderungan untuk melakukan kunjungan antenatal secara lengkap 5,75 kali dibandingkan responden yang menilai kualitas pelayanan antenatal kurang.

Tabel 5: Hubungan Variabel Kovariat dengan Kelengkapan Ibu Hamil Dalam Melakukan Kunjungan Antenatal Care

\begin{tabular}{lcc}
\hline \multicolumn{1}{c}{ Variabel Kovariat } & $\mathrm{p}$ value & $\mathrm{OR}$ \\
\hline Umur & 0,83 & 1,2 \\
\hline Pendidikan & 0,012 & 2,4 \\
\hline Pengetahuan & 0,10 & 2,44 \\
\hline Paritas & 0,94 & 0,89 \\
\hline Pekerjaan & 0,106 & 0,55 \\
\hline Sikap & 0,000 & 3,79 \\
\hline
\end{tabular}

Berdasarkan hasil uji statistik diperoleh nilai $p$ dibawah 0,05 adalah variabel pendidikan dan variabel sikap, 
sedangkan untuk variabel umur, pengetahuan, paritas dan pekerjaan di atas 0,05 . Ini berarti hanya variabel pendidikan dan Sikap yang berhubungan langsung dengan kelengkapan ibu hamil dalam melaksanakan kunkujan K4.

\section{PEMBAHASAN}

Berdasarkan hasil penelitian didapatkannya hubungan hubungan antara kelengkapan ibu hamil dalam melakukan antenatal dengan kualitas pelayanan antenatal. Analisis keeratan hubungan dua variabel didapat $\mathrm{OR}=5,75$. Sedangkan hasil analisis ariabel koariat yang mempengarugi kualitas pelayanan antenatal didapatkan variabel pendidikan dan sikap.

\section{Menurut Direktur Jendral}

Pelayanan Medik Departemen Kesehatan (1993), kualitas pelayanan kesehatan adalah suatu derajat kesempurnaan pelayanan yang dapat memenuhi kebutuhan masyarakat konsumen akan pelayanan kesehatan yang sesuai dengan standar profesi dan sumber daya yang tersedia secara wajar, efisien dan efektif serta diberikan secara aman dan memuaskan sesuai norma, etika, hukum dan sosial budaya dengan memperhatikan keterbatasan dan kemampuan pemerintah dan masyarakat konsumen.

Mutu pelayanan kesehatan hanya dapat diketahui apabila sebelumnya telah dilakukan penilaian. Dalam praktek seharihari melakukan penilaian ini tidaklah mudah, penyebab utamanya tiap orang, tergantung latar belakang dan kepentingan masing-masing, dapat saja melakukan penilaian dan dimensi yang berbeda (Saifuddin, 2001). Menurut Notoatmodjo (1993), di dalam masyarakat terdapat bermacam-macam kelompok berbeda yang mempengaruhi harapan dan persepsi pasien. Perbedaan tersebut menggambarkan nilai kelompok dan kekuatan kelompok untuk memenuhi kebutuhan termasuk kebutuhan dalam bidang kesehatan. Perbedaan tersebut didasarkan karena perbedaan pendapat masyarakat, tingkat pendidikan, umur, jenis kelamin, agama serta perbedaan suku bangsa.

Penelitian Smith dan Matzner (Saifuddin, 2001) mencatat adanya perbedaan dimensi mutu. Untuk para penyelenggara pelayanan kesehatan, dimensi mutu pelayanan kesehatan yang dipandang paling penting adalah pengetahuan ilmiah yang dimiliki (80\%), perhatian secara pribadi kepada pasien (60\%), keterampilan yang dimiliki $(50 \%)$, efisiensi pelayanan kesehatan $(45 \%)$ serta kenyamanan pelayanan yang dirasakan pasien $(8 \%)$. Sedangkan untuk pasien sebagai pemakai jasa pelayanan kesehatan yang dipandang paling penting adalah efisiensi pelayanan kesehatan $(45 \%)$, perhatian petugas secara pribadi kepada pasien $(40 \%)$, keterampilan yang dimiliki petugas $(35 \%)$ serta kenyamanan pelayanan kesehatan yang dirasakan pasien $(35 \%)$. Bertitik tolak dari adanya dua pembatasan dimensi mutu maka dapat dirumuskan apa yang disebut dengan mutu pelayanan kesehatan. Mutu pelayanan kesehatan menunjuk pada tingkat kesempurnaan pelayanan kesehatan, yang disatu pihak dapat menimbulkan kepuasan pada setiap pasien sesuai dengan dengan tingkat kepuasan rata-rata penduduk, serta di pihak lain tata cara penyelenggaraannya sesuai dengan kode etik dan standar pelayanan profesi yang telah ditetapkan (Saifuddin, 2001).

Pelayanan berkualitas dapat dikatakan sebagai tingkat pelayanan yang memenuhi standar yang telah ditetapkan. Standar adalah rumusan tentang penampilan atau nilai yang diinginkan yang mampu dicapai berkaitan dengan parameter yang telah ditetapkan. Standar pelayanan berguna dalam penerapan norma dan tingkat kinerja yang diperlukan untuk mencapai hasil yang diinginkan. Dengan adanya standar pelayanan yang dapat dibandingkan dengan pelayanan yang diperoleh, maka masyarakat akan mempunyai kepercayaan yang lebih mantap terhadap pelaksanaan pelayanan (Depkes RI, 1999). 
Pelayanan antenatal adalah pelayanan kesehatan yang diberikan kepada ibu selama kehamilannya sesuai dengan standar pelayanan antenatal yang telah ditetapkan dalam buku pedoman pelayanan antenatal bagi petugas Puskesmas (Depkes RI, 2004). Pelayanan antenatal yang selengkapnya mencakup banyak hal yang meliputi anamnesis, pemeriksaan fisik (umum dan kebidanan), pemeriksaan laboratorium atas indikasi serta intervensi dasar dan khusus (sesuai risiko yang ada termasuk penyuluhan dan konseling) (Depkes RI, 2004)

Pelayanan antenatal sesuai standar meliputi anamnesis, pemeriksaan fisik (umum dan kebidanan), pemeriksaan laboratorium rutin dan khusus, serta intervensi umum dan khusus (sesuai risiko yang ditemukan dalam pemeriksaan).

Tujuan antenatal adalah untuk mencegah, mengatasi masalah/penyakit (termasuk dampak dari kehamilan) dan memberikan informasi yang lengkap kepada ibu dan keluarganya serta memberikan nasehat tentang kehamilan yang sehat, persalinan, penyembuhan post natal termasuk perawatan bayi baru lahir, promosi inisiasi menyusu dini dan memberi bantuan dalam menentukan kehamilan berikutnya untuk memperbaiki outcome kehamilan.

Pendidikan berpengaruh pada cara berpikir, tindakan dan pengambilan keputusan seseorang dalam menggunakan pelayanan kesehatan, semakin tinggi pendidikan ibu maka akan semakin baik pengetahuannya tentang kesehatan. Pendidikan yang rendah menyebabkan seseorang acuh terhadap program kesehatan, sehingga mereka tidak mengenal bahaya yang mungkin terjadi walaupun ada sarana yang baik belum tentu mereka tahu menggunakannya (Martadisubrata, 1987).

Penelitian Simanjuntak (2002) mendapatkan ada hubungan antara kunjungan antenatal K4 sesuai standar dengan tingkat pendidikan, responden yang mempunyai tingkat pendidikan tinggi kecenderungan untuk melakukan kunjungan antenatal sesuai standar 2,75 kali lebih besar dibanding yang berpendidikan rendah. Penelitian Junaidi (2005) mendapatkan ibu dengan jenjang pendidikan tinggi mempunyai kecenderungan lebih besar memanfaatkan pelayanan antenatal berkualitas dibandingkan ibu dengan jenjang pendidikan rendah.

Sikap merupakan reaksi atau respon yang masih tertutup dari seseorang terhadap suatu stimulus atau obyek. Manifestasi sikap itu tidak dapat langsung dilihat, tetapi hanya dapat ditafsirkan terlebih dahulu dari perilaku yang tertutup, sikap merupakan kesiapan untuk bereaksi terhadap obyek dilingkungan tertentu sebagai suatu penghayatan terhadap obyek. Sikap belum merupakan suatu tindakan atau aktivitas, tetapi merupakan predisposisi tindakan atau prilaku (Notoatmodjo, 1993)

Sadik (1996) menyatakan bahwa sikap ibu yang positif terhadap pelayanan antenatal, lebih baik dalam pemanfaatan pelayanan antenatal dibandingkan dari ibu yang bersikap negatif. Hasil penelitian Simanjuntak (2002) memperlihatkan responden yang bersikap positif lebih banyak melakukan kunjungan antenatal K4 sesuai standar dibanding yang bersikap negatif.

\section{KESIMPULAN}

Dari hasil penelitian dan pembahasan yang dilaksanakan dapatlah ditarik kesimpulan bahwa kelengkapan ibu hamil dalam melakukan antenatal di Kabupaten Lampung Timur tidak terlalu jauh berbeda antara yang lengkap dengan yang tidak lengkap (60 berbanding 40). Sedangkan kualitas pelayanan antenatal yang diberikan oleh petugas yang meliputi aspek keramahan, komunikasi, dan tindakan pelayanan sudah cukup baik, hampir sama antara kualitas pelayanan yang baik dengan yang kurang baik ( 49 berbanding 51).

Berdasarkan analisis lebih lanjut dapat disimpulkanbahwa kualitas pelayanan antenatal berhubungan dengan 
kelengkapan ibu hamil dalam melakukan antenatal setelah dikontrol oleh pengetahuan, dan sikap, menunjukan nilai pelayanan antenatal yang diterimanya semakin berkualitas untuk melakukan pemeriksaan antenatal secara lengkap dibandingkan dengan ibu yang menilai kualitas antenatal yang diterimanya kurang baik.

Berdasarkan penelitian yang dilaksanakan dan kesimpulan yang diambil dapat disarankan kepada dinas kesehatan untuk melakukan pembinaan terhadap petugas kesehatan agar lebih ramah, lebih komunikatif dan lebih terampil dalam memberikan pelayanan pada ibu hamil.

Selanjutnya juga dapat melakukan pembinaan terhadap petugas KIA di Puskesmas Kabupaten Lampung Timur agar pelayanan antenatal bisa dilakukan sesuai standar sehingga ibu hamil melakukan pemeriksaan secara teratur dan lengkap da melakukan pelatihan bagi tenaga kesehatan khususnya pemegang program KIA untuk meningkatkan kemampuan petugas agar pelayanan yang diberikan berkualitas dan sesuai standar. Dinas Kesehatan juga perlu melakukan monitoring ke puskesmas untuk memastikan pelayanan antenatal telah dilaksanakan sesuai standar dan bila ditemukan hambatan dapat diatasi dengan segera.

Sedangkan bagi Puskesmas dan petugasnya disarankan agar petugas puskesmas khususnya petugas KIA dalam memberikan pelayanan antenatal harus bersikap ramah, komunikatif dan kompeten sehingga kualitas pelayanan akan lebih baik.

Petugas KIA dalam memberikan pelayanan antenatal sesuai dengan standar yang telah ditetapkan yaitu Standar Pelayanan Kebidanan (SPK), sehingga ibu hamil akan memeriksakan kehamilannya secara lengkap dan teratur.

3. Meningkatkan penyuluhan pada ibu hamil ketika melakukan pelayanan antenatal agar pengetahuan ibu hamil meningkat, dan menekankan bahwa semua kehamilan bisa berisiko sehingga ibu mengerti akan pentingnya melakukan antenatal, bukan hanya merupakan kegiatan rutin yang dirasakan tidak ada manfaatnya.

\section{DAFTAR PUSTAKA}

Depkes RI. 1991. Pedoman Kerja Puskesmas, Jilid I. Jakarta: Depkes RI.

Depkes RI. 1992. Pedoman Pelayanan Antenatal di Wilayah Kerja Puskesmas. Jakarta: Depkes RI.

Depkes RI. 2005. Kebijakan dan Strategi Nasional Kesehatan Reproduksi di Indonesia. Jakarta: Depkes RI.

Depkes RI. 2008. Laporan Riskesdas 2007. Jakarta: Balitbangkes Kemenkes RI.

Dinas Kesehatan Propinsi Lampung. 2009. Profil Kesehatan Provinsi Lampung Tahun 2009. Bandar Lampung: Dinke Provinsi Lampung.

Dinas Kesehatan Kabupaten Lampung Timur. 2010. Profil Kesehatan Kota Kabupaten Lampung Timur 2009, Sukadana: Dinkes Kabupaten Lampung Timur.

Junaidi, Turno. 2005. Hubungan Pengetahuan Ibu tentang Pemeriksaan Kehamilan dengan Kualitas Pemanfaatan Pelayanan Antenatal di Kota Bogor tahun 2004, Tesis Program Pasca Sarjana Universitas Indonesia. Depok: Pepustakaan Universitas Indonesia.

Notoatmodjo, S. 1993. Pengantar Pendidikan Kesehatan dan ilmu prilaku kesehatan. Yogyakarta: Rineka Cipta.

Saifuddin. A.B., dkk. 2001. Buku Acuan Nasional Pelayanan Kesehatan Maternal dan Neonatal. Jakarta: Yayasan Bina Pustaka Sarwono Prawirohardjo.

Simanjuntak, Tumiar. 2002. Faktor-Faktor yang Berhubungan dengan Kunjungan Antenatal K4 di Kota Medan Propinsi Sumatra Utara tahun 2002. Tesis Program Pasca Sarjana Universitas Indonesia, Depok. 
WHO-Depkes RI-FKM-UI, 1999. Materi Ajar Modul Safe Motherhood. Jakarta: WHO-Depkes RI,
WHO. 2005. Provision of Effective Antenatal Care: Integrated Management of Pregnacy and Childbirth (IMPAC). Standards for Maternal and Neonatal Care. 